Relações Sociais - Fernanda Schaefer Rivabem

RESENHA

\title{
DIREITO PRIVADO E INTERESSES PÚBLICOS: UMA ANÁLISE À LUZ DE GIORGIO OPPO
}

\author{
Fernanda Schaefer Rivabem*
}

\begin{abstract}
RESUMO
Giorgio Oppo, no artigo intitulado Direito Privado e Interesses Públicos, produz uma crítica ao modelo liberal elaborado para o Direito Privado e que levou à moderna dicotomia entre Público e Privado. As molduras clássicas, fundadas nos pilares: ser, ter e agir, são analisadas e criticadas pelo autor que as identifica como categorias atemporais, desideologizadas e ineficientes e, portanto, distantes da realidade social. A presente resenha tem por objetivo apresentar o conteúdo do artigo, produzindo uma conseqüente análise crítica, tendo como ponto de partida as idéias de publicização, descodificação, descentralização, constitucionalização e repersonalização do Direito Privado. Pretende-se, com isso, reconhecer, no texto, a travessia em curso que exige dos operadores do Direito uma posição participativa e questionadora.
\end{abstract}

Palavras-chave: direito privado; interesses públicos; publicização; harmonização.

SUMÁRIO: I. JUSTIFICATIVA DA METODOLOGIA ESCOLHIDA II. RESENHA. II.1 A ESCOLHA DO TÍtUlo II. 2 O SER II. 3 O TER E O AGIR II. 3.1 DO CONTRATO. II. 3.2 DA EMPRESA II. 3.3 DAS SOCIEDADES III. CONCLUSÃO IV. REFERÊNCIAS.

\footnotetext{
* Advogada em Curitiba-PR, graduou-se em Direito pela Pontifícia Universidade Católica do Paraná, campus Curitiba, em 2000. Especializou-se em Direito Processual Civil pela mesma instituição em 2003. Foi bolsista CAPES no Mestrado em Direito Econômico e Social da Pontifícia Universidade Católica do Paraná, curso que concluiu em março de 2005. Atualmente é doutoranda em Direito das Relações Sociais na Universidade Federal do Paraná. Autora de obras e artigos sobre responsabilidade médica e Biodireito; integrante do Grupo de Pesquisa em Biodireito, vinculado ao curso de Pós-Graduação Stricto Sensu da PUC-PR; professora de Direito Civil do curso de Direito das Faculdades Radial; professora de Direito Civil e Bioética do curso de Direito da Universidade Tuiuti do Paraná, ambas de Curitiba. Membro da Comissão de Ensino Jurídico da OAB-PR.
} 


\section{I - JUSTIFICATIVA DA METODOLOGIA ESCOLHIDA}

Para a realização do estudo, face à complexidade do texto lido ${ }^{1}$, preferiu-se adotar a seguinte metodologia: à medida que se realiza a síntese da obra, far-se-á em contrapartida a sua análise textual, temática e interpretativa, problematizando-se os temas propostos pelo autor. Optou-se por essa forma de realizar o relatório em virtude da dificuldade de simplesmente se resumir em poucas palavras o que foi lido para após proceder a exigida análise.

\section{II - RESENHA}

\section{II.1 A ESCOLHA DO TÍTULO}

Giorgio Oppo, em sua introdução, inicia justificando a escolha do título: Diritto Privato e Interessi Pubblici. Em sua justificativa, começa indicando a clássica distinção, construída na Modernidade, entre interesse público e interesse privado. Por interesse público, afirma, entendem-se aqueles fatos próprios, regulados e geridos pelo Estado e por interesse privado, as regras de tutela e conduta entre e para particulares.

Sobre a clássica dicotomia indicada pelo autor, é importante proceder algumas breves considerações. A distinção ${ }^{2}$ entre o Direito Público e o Direito Privado fixou-se no Direito Romano em virtude da necessidade de elaboração de regras capazes de diferenciar os bens do Império Romano daqueles do patrimônio particular do

${ }^{1}$ OPPO, G. Diritto privato e interessi pubblici. Rivista di Diritto Civile. Padova: CEDAM, a. 40, n. 1, p. 25-41, 1994.

${ }^{2}$ É distinção que, inicialmente, não se mostra errônea, mas com o passar do tempo demonstra ser incompleta e, nas palavras de Miguel Reale, "há duas maneiras complementares de fazer-se a distinção entre Direito Público e Privado, uma atendendo ao conteúdo; a outra com base no elemento formal, mas sem cortes rígidos [...]". REALE, M. Lições preliminares de direito. 27. ed. São Paulo: Saraiva, 2003. 


\section{Direito Privado e InTeresses Públicos: UMA ANÁlise À LUZ DE GiORgio OPPo}

imperador; e sobre a necessidade de conceder alguns direitos subjetivos aos estrangeiros.

Então, dessa idéia inicial, firmaram-se as seguintes molduras: Direito Público é o destinado a disciplinar os interesses gerais da coletividade ou interesses públicos; o Direito Privado é o conjunto de preceitos que regulam as relações interprivadas, o locus normativo privilegiado do indivíduo. Molduras que, à medida que a humanidade evoluiu, foram sendo adaptadas política e socialmente ${ }^{3}$ e que chegaram à moderna construção: o interesse público consiste em tudo aquilo em que é titular o Estado e interesse particular naquilo que é titular o indivíduo, interesses que estão, em regra, em contraposição.

A dicotomia romana ganhou especial relevância ao ser encampada pelo Estado Liberal que passou a ver nas codificações uma forma eficaz de organização e regulação da sociedade, bem como, do próprio Estado, mas que, desvirtuando a sua natureza inicial de direito do cidadão, concebeu o Direito Privado como destinado a proteção de direitos individuais, criando a categoria abstrata denominada "sujeito de direitos". Então, no século XIX, o liberalismo jurídico consagrou a completude e unicidade do Direito, que passou a ter como única fonte o Estado e, nesse contexto, propagou-se a idéia do Código Civil como a "Constituição do Direito Privado", tendo como referência apenas o cidadão dotado de patrimônio, destinando-se aos interesses privados. Restando ao Direito Público preocupar-se apenas com interesses públicos.

Com o enfraquecimento do Estado Liberal e a evolução das relações sociais, a compartimentação do Direito em Público e Privado mostrou-se atemporal, desideologizada, ineficiente e distante da nova realidade social; a prevalência do ter sobre o ser impediu a valorização da dignidade humana, o respeito à justiça

\footnotetext{
${ }^{3}$ Vale ressaltar que, inicialmente, os espaços públicos e privados podiam ser facilmente identificados, como por exemplo: na Antigüidade a Ágora contrapunha-se a casa do pater familias. Já na Idade Média, com a centralização do poder nas mãos dos senhores feudais, o espaço público foi consideravelmente reduzido, sobrepondo-se os interesses particulares sobre os coletivos, o que tornou a distinção um tanto quanto irrelevante. A necessidade da distinção só volta a ser invocada na Idade Moderna pelos Estados Absolutistas e conseqüente reconstrução dos espaços públicos.
} 
distributiva e à igualdade material. O exercício de direitos vinculados à apropriação de bens, resultou na criação de paradoxos: como a existência de pessoas que não são sujeitos de direitos por não se enquadrarem na moldura classicamente imposta e, por conseqüência, a não regulação de diversas relações sociais (não Direito). Nesse sentido, ensina Ricardo Luis Lorenzetti:

\begin{abstract}
No plano público há uma relação entre desiguais, porque o Estado é forte, está dotado de império, suas decisões são inatacáveis; contrariamente, no Direito Privado há dois sujeitos em paridade, que têm relações horizontais. Contudo, atualmente ninguém nega que no plano privado há desigualdades muito importantes entre os indivíduos, talvez muito mais relevantes que aquelas que existiram com respeito ao Estado. Por isto é que aparece cada vez mais força a norma imperativa no Direito Privado, que se impõe aos particulares em assuntos sensíveis ao interesse público ${ }^{4}$.
\end{abstract}

Assim, a dicotomia público-privado passou a sofrer forte crítica, em especial porque: a) a expressão público tornou-se equívoca quando começou a ser utilizada como sinônimo de interesses sociais, interesses indisponíveis e interesses da coletividade; b) muitas vezes o próprio legislador abandona o conceito de interesse público como interesse do Estado e passa a identificá-lo como bem geral, ou seja, o interesse geral da coletividade ou o interesse da coletividade como um todo; c) passouse a reconhecer a existência de uma categoria intermediária de interesses que são compartilhados por grupos, classes ou categorias de pessoas, o que tem originado microssistemas de tutela. Conseqüência da atual conjuntura: o público privatiza-se e o privado torna-se público 5 .

Em oposição à manutenção da dicotomia público-privado foi proposta a publicização do Direito Privado que compreende o processo de crescente intervenção estatal nas relações privadas, característica do Estado Social. A publicização do Direito Privado deu-se, num primeiro momento, com a denominada descodificação que, no Brasil, se operou com a edição de um número significativo de leis

\footnotetext{
${ }^{4}$ LORENZETTI, 1998, p. 225.

${ }^{5}$ Ibidem, p. 226.
} 


\section{Direito Privado e InTeresses Públicos: UMA ANÁlise À LUZ DE GiORgio OPPo}

extravagantes, o que provocou, indubitavelmente, a descentralização do Direito Privado (antes centralizado na idéia de monossistema do Código Civil) para atender às necessidades políticas e sociais.

Também reflexo dessa nova concepção do Direito Civil foi a recepção na Constituição Federal de temas antes classificados pela dicotomia clássica como afetos apenas ao Direito Privado. A constitucionalização do Direito Privado provoca transformações substanciais na forma de se compreender as relações interprivadas. Deixa-se de se buscar espaços distintos para se buscar uma unidade hermenêutica, busca que também se revela no texto ora em análise no qual Giorgio Oppo procura reconstruir o que ele considera como os pilares desse sistema clássico privatístico: ser, ter e agir (ou pessoas, bens e atos).

Assim, a publicização do Direito Privado tornou mais nítido o pretenso fim da dicotomia Direito Público e Direito Privado. Tal fenômeno traz em si a renovação da estrutura da sociedade e a adaptação do Direito à nova realidade econômico-social, o que não pode ser tido, no entanto, apenas como uma adaptação do modelo vigente para atender a realidade que se apresenta, como salienta o próprio autor.

Giorgio Oppo, reconhecendo a necessidade de aproximar o público do privado e vice-versa, e defensor das transformações que ora se fazem impor, não propõe a prevalência do público sobre o privado, mas sim a reconstrução do sistema jurídico clássico, adotando-se a harmonização entre esses interesses. Nesse contexto, o autor, justificando o título adotado, procura contrapor ou justapor os interesses dos privados aos interesses gerais, ao menos no senso dos interesses de cada um e de todos, radicados na essência do homem e na consciência social.

Após explicar a adoção do título escolhido para o artigo em análise, o autor passa a discorrer sobre o Direito Privado sobre os três enfoques dos princípios privatísticos: ser, ter e agir (ou pessoas, bens e $\operatorname{atos}^{6}$ ). Destaca que em nenhum desses

${ }^{6}$ O Direito clássico moderno foi construído sobre três pilares considerados inabaláveis: propriedade, família e contrato. A sociedade contemporânea percebeu que tais pilares não podem ser estáticos e abstratos e tão-pouco emoldurados em significados dissociados da realidade social. Diante 
ângulos (juízos apriorísticos), a referência aos interesses gerais é uma não-referência ou uma referência de coincidência, de limite, de coordenação, de instrumentalidade, como é requerido pela própria unidade do ordenamento jurídico. Portanto, afirma, sustentar que a distinção entre interesses públicos e privados está superada ou em via de ser superada, não significa afirmar que esses interesses não possam concorrer, se confundir. O discurso adotado pelo autor então, será o de negar que o reconhecimento dos interesses públicos é suficiente para eliminar os interesses privados, e que aos interesses individuais podem ser reconhecidos interesses gerais.

\section{II.2 O SER}

Afirma Giorgio Oppo que a relação entre o direito das pessoas é ora de coincidência, ora de coordenação, ou seja, é de coincidência se considerados os direitos que a Constituição diz invioláveis (fundamentais, ou direitos do homem como chama a ordem internacional); é de coordenação se considerados como direitos da personalidade (como são chamados nos ordenamentos comunitários).

Destaca que os direitos invioláveis (liberdade, dignidade, eqüidade, integridade física e moral e sua defesa e o direito de não produzir prova contra si mesmo) são direitos do homem enquanto tal, não fundados em um ou outro ordenamento jurídico, mas que fundam a ordem jurídica e a sociedade humana e, portanto, a identificação desses direitos se faz do público no privado e não do privado no público.

Portanto, não é o interesse público que faz o direito à inviolabilidade do

de tal constatação, os juristas vêm sendo instados a contestar molduras secularmente impostas pelo Direito moderno, bem como a procurar respostas a outras possibilidades que hoje se apresentam. Ao sistema jurídico contemporâneo não é mais admitido simples embasamento no indivíduo-centrismo (próprio do século XVIII), sob pena de permitir que muitas situações fáticas não recebam a tutela adequada do Direito. 


\section{Direito Privado e InTeresses Públicos: UMA ANÁlise À LUZ DE GiORgio OPPo}

privado, mas o direito privado é, de per se de interesse geral e deve ser tratado juridicamente como tal. O primeiro interesse de um e de outro é o homem: a primeira conseqüência para o Direito é que não se configura disponibilidade da correspondente situação jurídica na parte do titular, nem na parte do outro, nem na parte da lei, nem é passível de revisão constitucional.

Quer dizer o autor, que na superação da dicotomia entre público e privado busca-se a preservação dos interesses coletivos e da dignidade da pessoa humana ${ }^{7}$, valorizando-se o ser sobre o ter (repersonalização do Direito Privado), numa verdadeira inversão dos valores clássico-liberais, não se podendo, nesse contexto, falar em produção normativa definitiva e final.

Por isso, afirma o autor, é melhor falar em direitos do homem do que em direitos da pessoa, já que quando se fala do homem e se reconhece a sua existência, nenhum interesse ou valor apriorístico (individual ou coletivo) pode lhe ser contraposto, senão apenas aquele de existência de outro homem.

Reconhece Giorgio Oppo que na sociedade atual, no entanto, há problemas angustiantes que colocam em conflito o homem e o interesse geral dos homens: aborto, eutanásia, suicídio, discriminação, conflitos de etnias, drogas, etc. e cuja solução, afirma, deve ter por enfoque a dignidade do homem já existente ou ainda existente. Portanto, o interesse geral sobre o homem não pode impor somente respeito e atenção, mas ação, segundo o dever constitucional da solidariedade.

Sustenta, no entanto, que diverso discurso é o dos direitos da personalidade (identidade, imagem, manifestação de pensamento, privacidade...) que são direitos individuais considerados na coletividade, em que se coordena o caráter humano e o caráter social do direito e do direito privado. Os direitos de personalidade são frutos da

${ }^{7}$ Ensina Danilo DONEDA (DONEDA, D. Da privacidade à proteção de dados pessoais. Rio de Janeiro: Renovar, 2006, p. 71) "o cristianismo, ao reconhecer no ser humano um princípio divino e eterno, formou a base para a construção da noção da dignidade da pessoa humana, que passava a ser considerada não apenas em si própria, porém também em função de suas aspirações e potencialidades - na lição de Del Vecchio, 'a sede, por assim dizer, da sua dignidade ético-jurídica não é propriamente nela, mas além dela'". 
tentativa, em especial da doutrina alemã do século XIX, de transformar a pessoa em um ponto de referência normativo que represente um valor em si; mas que hoje representam uma exemplar demonstração das transformações ocorridas na busca da prevalência do ser sobre o ter nos mais diversos ordenamentos jurídicos ${ }^{8}$, uma vez que deixam de corresponder a meros direitos subjetivos de "sujeitos de direitos".

Sob esse aspecto, não há dúvidas de que as relações entre Direito e personalidade humana são um dos grandes problemas da Filosofia do Direito, assim como o são para os que ainda sustentam a utilidade da dicotomia público-privado, justamente porque ao encampar tais direitos, o Direito Privado (em especial o Direito Civil) passa a considerar o homem e a sociedade em seu todo, o que, sem dúvida afeta dois grandes pilares dos Códigos oitocentistas: propriedade e contrato ${ }^{9}$. Nesse sentido, ressalta Danilo Doneda:

O impacto sentido pelo ordenamento ao recepcionar a idéia de personalidade proporcionou inevitáveis reflexos no conceito de sujeito de direito [tão 'bem' definido pelo Direito moderno], por muitos reputado como um instrumento demasiado abstrato e tecnicizado para abarcar as vicissitudes da personalidade humana. [...]. A crise do sujeito foi uma conseqüência natural neste contexto ${ }^{10}$.

A sociedade contemporânea, ciente de que o ser humano não pode mais ser protegido por categorias abstratas e atemporais criadas pelo modelo jurídico clássico, firmou a idéia de que personalidade jurídica, portanto, não pode estar fixada em um caráter quase que completamente instrumental e neutro (pretendido pelo Direito

${ }^{8}$ Vale ressaltar que o seu reconhecimento pela legislação não faz excluir hipóteses nela não previstas, pois sua leitura deve ser feita à luz das cláusulas gerais de proteção da personalidade; de tutela e promoção da pessoa humana.

${ }^{9}$ Afirma Danilo DONEDA (ibidem, p. 79) que "institutos tradicionais perderam assim algo de sua pretensa estabilidade, por terem sido obrigados a responder a demandas mais complexas; assim, a propriedade viu seu caráter absoluto ser desdito pelas limitações que lhe eram postas; a autonomia da vontade deu lugar a uma dialética de autonomia privada, além de muitos outros exemplos cuja menção pode ser substituída pela sensação do tempo transcorrido ao eco das palavras de Savatier, elle était si belle et si simple la notion du contrat dans le Code, em sua sincera devoção nostálgica ao Code de Napoléon".

${ }^{10}$ Ibidem, p. 83. 


\section{Direito Privado e InTeresses Públicos: UMA ANÁlise À LUZ DE GiORgio OPPo}

Privado) e cujas premissas, obviamente, não mais se coadunam com a realidade. Passa-se a compreender que a projeção da pessoa no ordenamento não pode ser um dado fixado em juízos apriorísticos intimamente vinculados a meros direitos subjetivos. Assim, o Código Civil, ao reconhecer os direitos de personalidade como direitos inerentes a qualquer pessoa, deixa de representar uma tradição que procurava separar abstratamente interesses individuais e interesses gerais.

Conclui Giorgio Oppo, que os direitos invioláveis e direitos da personalidade não estão fora do Direito Privado porque envolvem direito gerais, mas que da assimilação pelo público e da sujeição ao público pode vir uma maior tutela, bem como uma ameaça a toda a existência.

Assim, a neutralidade do Direito como fruto do conjunto de relações lógicas impostas pelo modelo liberal clássico não encontra mais respaldo social. Busca-se a funcionalização e vinculação ao contexto histórico, o que provoca um pluralismo jurídico que reconhece, na perspectiva interdisciplinar, a convivência e intersecção de relações públicas e privadas, vinculando-se lei e realidade social, visando uma maior proteção ao ser do que ao ter, ou seja, a prevalência de cláusulas gerais, como a tutela da dignidade da pessoa humana. Nesse sentido, afirma Danilo Doneda:

Este processo de convergência em torno da pessoa, apesar de possuir antigas raízes, foi particularmente acelerado e moldado pelas condições específicas do século passado [...]. Nesse contexto, desenvolve-se a idéia de estado social, no qual o ordenamento jurídico assume as funções de estabelecer e promover uma hierarquia de valores, privilegiando a pessoa humana através da Constituição que deixa de ser um instrumento de cunho basicamente político para tornar-se o ponto de convergência de todo o ordenamento - que, com isso, deixa de lado a pretensão de constituir-se em um sistema neutro. A tarefa incluía a adequação do instrumental jurídico a uma sociedade democrática e de novas características, fruto do início de uma experiência de inclusão social ${ }^{11}$.

Portanto, o reconhecimento da pessoa como valor em si mesmo faz com que o ordenamento aproxime o público do privado e vice-versa, na busca da plena tutela e

\footnotetext{
${ }^{11}$ Ibidem, p. 64-65.
} 
promoção da pessoa humana.

\section{II.3 O TER E O AGIR}

Analisando os bens e os direitos sobre eles, em especial a propriedade, Giorgio Oppo afirma que o interesse geral assume uma nova colocação e função, segundo convencimento difuso de limite: limite da fruição e limite da disposição.

Ensina que o interesse geral aqui não opera como dever de ação nem como pretensa ação, mas como sobrecarga. Assim, a relação com o interesse geral não se exaure nos termos da proclamada função social, mas é nela mesma estimada, no seu exercício e na acessibilidade correspondente, o que a faz absorver uma síntese de outros valores, em especial a utilidade social. Nesse sentido, é a função assegurada pela lei, e a propriedade garantida pela lei, porque consideradas como fruição geral dos bens pela coletividade e forma de promoção do ser humano em sociedade.

Mas, afirma o autor, o fundamento comum e essencial da aparência de bem (público ou privado) depende da diversa incidência que sobre uma ou outra categoria de bem pode haver em um ou outro momento histórico, o interesse geral. E, por isso, os bens de consumo, que se situam como centrais e não tocados pela função social, serão funcionalizados em certas conjunturas.

Portanto, discorre o autor, que emerge uma possível polivalência do instituto privatístico (propriedade) sobre o plano da correspondência entre o interesse individual e o interesse geral junto com o diverso valor que o mesmo instituto pode assumir em mão pública ou em mão privada. Confere-se ao ordenamento positivo o dever de estabelecer e graduar a relação entre a propriedade privada e a pública: considerandose minimamente que a propriedade privada é também enriquecimento do valor da pessoa, reconhecimento de sua legitimação e de sua operação social, meio de incrementar uma e outra, forma de reconhecimento do trabalho. Ou seja, contrariaria o 


\section{Direito Privado e InTeresses Públicos: UMA ANÁlise À LUZ DE GiORgio OPPo}

respeito ao homem se se pudesse reter a exclusão de cada um na participação dos bens, não pela participação de todos.

Assim, ressalta Giorgio Oppo que, se em certo sentido é excessivo considerar a propriedade coexistente com a liberdade e necessária garantia da mesma, ou seja, que essa concorre com exercício e desenvolvimento da liberdade das pessoas e atua como um interesse geral. É esta, no entender do autor, que deve ser a escolha constitucional.

Sob esse aspecto, passa a analisar se a escolha deve incidir entre o direito sobre o bem e o direito (ou liberdade) de exercitar uma atividade econômica sobre o bem ou com o bem, em particular com outros bens. Afirma que a intervenção do interesse geral não deve ser diretamente limitativa do direito privado à propriedade mas é resolutiva de um conflito interpretativo: o conflito entre propriedade e atividade, ou entre propriedade e empresa. A prevalência da segunda sobre a primeira, em particular na relação entre proprietário e empreendedor, refletiria, segundo o autor, em termos privatísticos uma escolha de interesse geral e aceitável apenas enquanto a reflete.

Recorrentemente, no presente relatório de leitura, tem-se afirmado que o Direito contemporâneo tem por foco a valorização da pessoa sobre o patrimônio e, outra não seria a justificativa às assertivas de Giorgio Oppo. Ao proteger (ou regular) o patrimônio, deve-se fazê-lo apenas e de acordo com o que ele significa: suporte ao livre desenvolvimento da pessoa ${ }^{12}$.

Ora, na busca da prevalência da dignidade da pessoa humana, necessário é também garantir-lhe o seu livre desenvolvimento e isso só é possível na combinação de situações subjetivas ${ }^{13}$ patrimoniais com situações subjetivas extrapatrimoniais. Daí

12 CORTIANO JÚNIOR, E. Alguns apontamentos sobre os chamados direitos de personalidade. In: FACHIN, L.E. (org.). Repensando fundamentos do direito civil brasileiro contemporâneo. Rio de Janeiro: Renovar, 2000. p. 33.

13 Explica Eroulths CORTIANO JUNIOR (ibidem, p. 33-34) que "a situação subjetiva caracteriza-se como a posição de um indivíduo frente ao direito, com a conseqüente atribuição de capacidade de ação (que pode exprimir-se através de várias formas, como por exemplo o direito 
Revista Eletrônica do CEJUR, Curitiba-PR, a. 2, v. 1, n. 3, ago./dez. 2008

a opção constitucional e infraconstitucional pela funcionalização da propriedade e do contrato, uma vez que, na atual sociedade, o Direito Privado (em especial o Direito Civil) não pode mais restringir-se a possibilitar a apropriação de bens.

Cabe aqui fazer breves considerações sobre o Direito Privado e a opção pela funcionalização de alguns institutos. Afirma Paulo Nalin que:

Quando primeiramente se aborda o tema da funcionalização não se pode ignorar que a busca é, em verdade, por ma nova função singular do contrato [e da propriedade]. O contrato, assim como a propriedade e a família, sempre tiveram suas respectivas funções atribuídas (funzione attributiva atrelada ao princípio proprietário), ora em conservação do poder econômico em favor de alguma classe social (propriedade à burguesia), ora em tutela da família legalmente permitida (matrimônio) e não de qualquer outra ${ }^{14}$.

Assim, continua Paulo Nalin:

Funcionalizar, na perspectiva da Carta de 1988, significa oxigenar as bases (estruturas) fundamentais do Direito com elementos externos à sua própria ciência. [...]. É romper com a auto-suficiência do Direito, hermético em sua estrutura e tecnicismo, outrora mais preocupado com os aspectos formais das regras, do princípio e do instituto, que com sua eficácia social. Por isso, a função perseguida é a social. Funcionalizar, sobretudo, em nosso contexto, é atribuir ao instituto jurídico uma utilidade ou impor-lhe um papel social $[\ldots]^{15}$.

Não é outra a perspectiva trabalhada por Giorgio Oppo, ou seja, atribuir interesses gerais a institutos considerados próprios do Direito Privado é conferir-lhes utilidade social e, portanto, aproximar-lhes da realidade e das necessidades sociais. Assim, o direito de "ter" não deve mais ser encarado apenas em sua perspectiva indivíduo-centrista, mas, em especial, como forma de realização do homem em sociedade.

subjetivo) $[\ldots]^{\prime \prime}$.

14 NALIN, P. Do contrato: conceito pós-moderno. Em busca de sua formulação na perspectiva civil-constitucional. Curitiba: Juruá, 2001, p. 215.

${ }^{15}$ Ibidem, p. 217. 


\section{Direito Privado e INTEResses PÚblicos: UMA ANÁLISE À LUZ DE GIORgIo OPPO}

Obviamente a opção progressista pela funcionalização não se impõe facilmente, em especial, nos países ainda fortemente influenciados pela tradição oitocentista (moderna). A funcionalização do contrato e da propriedade consiste em abordar a liberdade de "ter" em seus reflexos sobre a sociedade e não apenas no campo das relações interprivadas, opção que, portanto, se coaduna com a valorização dos interesses gerais face aos interesses meramente privados, em franca observância ao princípio constitucional da solidariedade.

\section{II.3.1 DO CONTRATO}

Na busca da harmonização dos institutos privados com os interesses gerais, Giorgio Oppo passa a discorrer sobre a atividade (ação) sobre os bens e os direitos sobre eles. Afirma que com os interesses gerais a atividade deve fazer relação mais com o ser do que com o ter. Ser e ter são como tais destinatários da tutela jurídica; o agir não é tutelado somente em função do fim que se propõe e do resultado que se consegue, mas também em função do próprio interesse, em termos objetivos e subjetivos que se realiza.

O autor passa a explorar os instrumentos privatísticos gerais do agir de modo juridicamente relevante que, em sua visão, são essencialmente três: o contrato; a empresa e a sociedade.

O contrato, afirma, é elemento essencial de base. Exprime a energia jurídica do privado, porque é o efeito jurídico que reclama o acordo dos particulares e porque necessita da manifestação do acordo e realiza a eqüidade das partes face ao Direito. Já a empresa e a sociedade são instrumentos complexos que utilizam o contrato inserindo-o no agir de uma organização pessoal e patrimonial. Também aqui, afirma Giorgio Opppo, a relação com os interesses gerais não é mais de indiferença ou de mérito. A relação com o interesse geral estabelece-se internamente na relação de noção de mérito, noção que variará de valor de acordo com a ordem jurídica e com a 
consciência social.

Ensina o autor que para o contrato o mérito é deduzido da seleção das causas típicas, isto é, da função que a lei os assinala e como os disciplina. Por si, o mérito significa seriedade, utilidade do resultado, mas agora, também, para além do plano individual. Também significa não contrariedade ao interesse geral: não contrariedade da função e do resultado, a não contrariedade entre o concreto conteúdo e a concreta atuação que é dada pelas normas imperativas e pelas cláusulas gerais ${ }^{16}$ que condicionam a validade ou governam a conduta na execução.

Destaca Giorgio Oppo que o mérito do contrato não é apenas a sua licitude ou busca do interesse geral, tão-pouco é apenas a conformidade ao interesse geral. O contrato é, por si, neutro respeito à busca do interesse geral e isso não significa que não possa vir a ser em concreto instrumento de atuação de tal interesse. Como a propriedade pode ser pública e privada, o contrato também pode ser, em termos subjetivos, público e privado. É público no âmbito da Administração Pública, o que não significa que migrou para o Direito Público, nem importa que a presença do sujeito público reste indiferente ao interesse geral e que não incida sobre a disciplina do ato. No contrato ainda prevalece a estrutura privatística, embora possa ser perfeitamente harmonizada com o interesse geral.

Assim, a verdade é que no contrato em geral se identifica um comportamento

${ }^{16}$ Ensina Alberto Gosson JORGE JÚNIOR (JORGE JÚNIOR, A.G. Cláusulas gerais no novo Código Civil. São Paulo: Saraiva, 2004, p. 22) que "as cláusulas gerais são normas jurídicas, originadas de um processo legislativo constitucionalmente previsto, que as posiciona na categoria formal de leis. São normas jurídicas dotadas de uma função peculiar, diferenciada das demais normas, por carregarem uma amplitude semântica ou valorativa maior do que a generalidade das disposições normativas". E completa Judith MARTINS-COSTA (MARTINS-COSTA, J. A boa-fé no direito privado. São Paulo: Revista dos Tribunais, 2000) que "consideradas do ponto de vista da técnica legislativa, a cláusula geral constitui, portanto, uma disposição normativa que utiliza, no seu enunciado, uma linguagem de tessitura intencionalmente aberta, fluida ou vaga, caracterizando-se pela ampla extensão do seu campo semântico, a qual é dirigida ao juiz de modo a conferir-lhe um mandato (ou competência) para que, à vista dos casos concretos, crie, completamente ou desenvolva normas jurídicas, mediante o reenvio para elementos cuja concretização pode estar fora do sistema; estes elementos, contudo, fundamentarão a decisão, motivo pelo qual, reiterados no tempo os fundamentos da decisão, será viabilizada a ressistematização destes elementos originariamente extrasistemáticos no interior do ordenamento jurídico". 


\section{Direito Privado e INTEResses PÚblicos: UMA ANÁLISE À LUZ DE GIORgIo OPPO}

de espera e de exigência diversa: não é apenas o momento de formação da vontade que é tutelado. Trata-se de espera e de exigência que devem ser conciliadas com todos; nessa conciliação que é posta pelo interesse geral, fixada na essencialidade do acordo, a limitação dos efeitos entre as partes, as regras de interpretação, a eqüidade das partes no plano patrimonial, a aplicação do dar e do ter (sinalagma) do direito geral das obrigações.

É nesse sentido que o contrato deve ser visto como instrumento de circulação econômica (porque não há como se desvincular dessa característica) cujo conteúdo não pode, ou pelo menos não deve, se contrapor a interesses gerais. E, ainda que em tempos de "reconstrução do Direito" não seja aconselhável formular novos conceitos, vale reforçar que o contrato, contemporaneamente, deve ser considerado uma relação complexa solidária e não mero acordo de vontades que apenas gera efeitos entre as partes contratantes.

Ressalte-se, por fim, que a liberdade contratual encontra-se hoje fortemente limitada pelos interesses gerais que aparecem tutelados por meio de normas de ordem pública; no entanto, vale dizer, a harmonização de interesses gerais e individuais não significa retirar a segurança jurídica do instituo, mas sim, reconhecer-lhe sua verdadeira vocação solidária, análise que deverá ser realizada in concreto.

\section{II.3.2 DA EMPRESA}

Continuando a explorar os instrumentos privatísticos referentes ao "ter", Giorgio Oppo, passa a tecer considerações com relação à empresa que considera também um modelo privatístico, tanto na organização, como nos mecanismos de ação.

Afirma que dois são os perfis sobre os quais a empresa envolve interesses gerais: pela sua intrínseca utilidade social e pelo seu poder ser empresa pública ou privada. Também são de interesse geral a coexistência e pluralidade de empresas; 
como é de interesse geral a acessibilidade à iniciativa econômica e o concurso de iniciativas econômicas. Nesse contexto, a disciplina privatística da empresa deve ser feita de um lado de norma de favor e de outro de norma de cautela e de tutela os interesses externos.

Portanto, a empresa não deve ser considerada neutro respeito ao interesse geral como o é o contrato. Não é neutra enquanto produtiva de nova utilidade. É, sim, neutro respeito ao fim da ação e ao fim ulterior da ação e aqui reside a diferença entre empresa pública e privada: o escopo de utilidade geral é estranho à empresa privada, mas é essencial à empresa pública.

Assim, a questão é saber se a disciplina fundamental privatística permite uma margem operacional para o interesse público na formação e gestão da relação com reflexos de ordem substancial e jurisdicional. Parece ao autor que sim, pois, o que importa afirmar é que a empresa, em qualquer mão, é verdadeiramente uma empresa e esta condição é inafastável também da empresa pública. Assim, percebe-se um redimensionamento da presença pública na economia.

Dessa forma, a supremacia do privado não se realiza com o cancelamento do público, mas com a comunicação ao público de regras, estruturas técnicas, métodos operativos que restituam crédito não só ao fim, mas como aos meios da empresa pública (como empresa de um sujeito público e como empresa em mãos públicas ${ }^{17}$ ).

Contrato e empresa, na visão do autor, estão intimamente ligados, trabalhando aquele em favor desta. Neste sentido, explica Sérgio Seleme:

A conceituação jurídica de empresa é das mais controvertidas, principalmente nos dias
atuais. Com efeito, não se chegou ainda a um consenso sobre a caracterização da empresa no
âmbito do Direito. Tende-se, francamente, ao posicionar-se a empresa no universo jurídico, a
privilegiar - no âmbito da regulação jurídica da Economia - o aspecto dinâmico
representado pela empresa, em substituição ao traço estático que representou a propriedade,

${ }^{17}$ Explica Giorgio Oppo que a empresa de um sujeito público é, por si, uma empresa em mãos públicas. Já a empresa patrimonializada e gerida pelo público não é necessariamente, em termos jurídicos, de um sujeito público, mas inegavelmente é pública no sentido econômico e político (são S.As.). 


\section{Direito Privado e InTEResses Públicos: uMa ANÁlise à luZ de Giorgio OPPO}

em consonância com a idéia de desmaterialização da riqueza. Ou seja, tende-se a identificar a empresa como uma atividade, vinculada à organização de uma série de fatores de conteúdo econômico para a prossecução de determinados fins (dentre eles, obviamente, o de gerar lucro $)^{18}$.

Outro não é o entendimento exposto no texto em análise, ou seja, ao se reconhecer a empresa também como objeto de interesses gerais, não se está a lhe retirar a finalidade de lucro, mas sim, se está a ressaltar sua utilidade social. Vale por fim dizer, que a função social predeterminada para a propriedade privada não diz respeito exclusivamente aos seus limites, ou seja, ao conferir utilidade social à empresa, imputasse a ela também um papel que vai muito além dos moldes privatísticos da propriedade e que, portanto, repercute sobremaneira na sociedade em que está inserida ${ }^{19}$.

\section{II.3.3 DAS SOCIEDADES}

Ainda discorrendo sobre o "ter" na estrutura privatística o autor aborda as sociedades. Afirma que a adoção de uma estrutura genericamente associativa para a consecução de um interesse geral apresenta problemas menores do que a adoção de uma estrutura propriamente societária uma vez que a escolha do escopo da associação é livre e de caráter não lucrativo se concilia bem com interesses não somente comuns mas também próprios de uma vasta coletividade. Já as sociedades podem ser estruturas

${ }^{18}$ SELEME, S. Contrato e empresa: notas mínimas a partir da obra de Enzo Roppo. In: FACHIN, L.E. (org.). Repensando fundamentos do direito civil brasileiro contemporâneo. Rio de Janeiro: Renovar, 2000, p. 269.

19 Nas palavras de Pietro PERLINGIERI (Il Diritto civile nella legalità costituzionale. Napoli, Itália: Edizioni Scientifiche Italiane, 1991, p. 226), atribuir função social à empresa não significa apenas afirmar uma intervenção "em ódio à empresa privada, mas torna-se a 'própria razão pela qual o direito de propriedade foi atribuído a um determinado sujeito', um critério de ação para o legislador, e um critério de individuação da normativa a ser aplicada para o intérprete chamado a avaliar as situações conexas à realização de atos e de atividades do titular". 
privatísticas tipicamente destinadas ao exercício de atividade econômica.

O autor retoma a idéia de que contrato e sociedade são institutos natos do Direito Privado e na estrutura privatística, mas não necessariamente privatísticos no fim do sujeito.

Assim, a adoção de Sociedades Anônimas (na forma codificada) não é neutra nem quanto ao fim, nem quanto ao sujeito que a constitui. $O$ fim deve ser lucrativo (aquisição e participação); a este fim (que é o momento essencial do contrato, da relação e dessa pessoa jurídica) se adequa a estrutura na democracia dos acionistas e no poder de decisão da maioria subordinado ao poder de controle e de tutela da minoria.

Nesse contexto, afirma Giorgio Oppo que estaria aberto um caminho à sociedades ditas especiais ou singulares, estrada sobre a qual se atenua progressivamente o significado causal e estrutural da fórmula societária para configurar a sociedade que se constitui sem contrato e sem pluralidade de sócios, que não têm escopo de lucro. Esta sociedade não nasce da autonomia, cujas decisões não decorrem do poder de acionistas, mas extra-socialmente em sede política.

Em contraponto o autor trabalha a idéia de privatização substancial da gestão de empresas públicas, embora ainda persistente e prevalente a participação patrimonial pública com derrogação. Nesse sentido, a privatização viria como reequilíbrio e renovação da economia e política entre público e o privado. A reflexão deve se dar sobre os meios e limites do discurso que conduzem a forma jurídica.

Conclui, afirmando que não se pode pretender que sejam realmente privatizados os entes públicos preexistentes, mas sim aqueles entes que possuem administração concretamente independente como forma de harmonização entre interesses gerais e interprivados.

Assim como se reconhece à empresa uma função social, reconhece-se às sociedades, nas suas diversas formas de organização, uma utilidade social que pode ser, na visão do autor, realizada por meio da adoção da forma associativa ou da implementação de privatizações substanciais. Independente da forma a ser adotada, o 


\section{Direito Privado e INTEResses PÚblicos: UMA ANÁLISE À LUZ DE GIORgIo OPPO}

que importa é que o escopo social seja observado e valorizado, a fim de garantir a adequação de sua atuação às exigências da realidade social.

\section{III - CONCLUSÃO}

Pode-se afirmar que o autor reconhece a travessia em curso e toma face a ela uma postura participativa e questionadora, levando-o a afirmar que o interesse público pode servir-se do interesse privado, mas não pode pedir ao Direito Privado mais do que esse pode dar, aceitando-se dele aquilo que é essencial.

Ressalta, no entanto, que o uso normativamente distorcido dos institutos do Direito mortifica tanto o público quanto o privado, atenuando as garantias, suscitando questões de legitimidade constitucional e causando danos à coerência e o prestígio do ordenamento jurídico. Portanto, quando se fala no fim da dicotomia público-privado, não se está a propor a plena prevalência dos interesses públicos, mas sim, uma harmonização desses interesses em benefício de uma sociedade mais humana e equilibrada, em que o ser prevalece sobre o ter.

Com essas assertivas, não pretende Giorgio Oppo defender o privado, mas afirmar a busca de interesses gerais face a interesses, até então, considerados eminentemente privados. Nesse contexto, pretende-se firmar a idéia de que o Direito deve captar a mensagem de seu tempo, ou seja, deve buscar uma postura mais ativa, promovendo a adequação do sistema classicamente construído às necessidades da sociedade contemporânea. Nas palavras de Eroulths Cortiano Junior: "revolta-se o direito contra as concepções que o colocavam como mero protetor de interesses patrimoniais, para postar-se agora como protetor direto da pessoa humana"20.

Ora, se o Direito é um fenômento profundamente social, não se pode admitir

\footnotetext{
${ }^{20}$ CORTIANO JR. Alguns apontamentos ..., p. 33.
} 
que continue dissociado da realidade que o compõe. A travessia que hoje se apresenta traz em si a síntese do passado, evidencia a complexidade das relações presentes e apresenta as diretrizes para um futuro que ainda não chegou. $\mathrm{O}$ importante, nesse contexto, é que o jurista não se acomode em repetir ou revisar velhos significados, mas sim, aceite os riscos da transformação e trabalhe na busca de conceitos e institutos que possam atender efetivamente a realidade social que se apresenta, superando o modelo clássico tecnicista e excessivamente neutro e essa proposta foi alcançada no artigo analisado.

\section{IV - REFERÊNCIAS}

BORGES, R.C.B. Disponibilidade dos direitos de personalidade e autonomia privada. São Paulo: Saraiva, 2005. (Col. Prof. Agostinho Alvim).

CACHAPUZ, M.C. Intimidade e vida privada no novo Código Civil brasileiro - uma leitura orientada no discurso jurídico. Porto Alegre: Fabris, 2006.

CORTIANO JÚNIOR, E. Alguns apontamentos sobre os chamados direitos de personalidade. In: FACHIN, L.E. (org.). Repensando fundamentos do direito civil brasileiro contemporâneo. Rio de Janeiro: Renovar, 2000.

Para além das coisas: breve ensaio sobre o direito, a pessoa e o patrimônio mínimo. In: RAMOS, C.L.N. et al (orgs.). Diálogos sobre direito civil: construindo uma racionalidade contemporânea. Rio de Janeiro: Renovar, 2002.

DONEDA, D. Da privacidade à proteção de dados pessoais. Rio de Janeiro: Renovar, 2006.

FACHIN, L.E. Teoria crítica do direito civil. 2. ed. Rio de Janeiro: Renovar, 2003.

(coord.). Repensando fundamentos do direito civil brasileiro contemporâneo. Rio de Janeiro: Renovar, 2000.

Luzes e sombras no diálogo entre direito e medicina. In: TEIXEIRA, S.F. (coord.) Direito \& medicina: aspectos jurídicos da medicina. Belo Horizonte: Del Rey, 2000. p. 13-120.

FOUCAULT, M. Microfísica do poder. [s.1.]: Graal, [s.d.]. 


\section{Direito Privado e InTeresses Públicos: uMa anÁlise à luZ de Giorgio OPPo}

O nascimento da clínica. 6. ed. Rio de Janeiro: Forense Universitária, 2004.

GEDIEL, J.A.P. Autonomia do sujeito e biopoder. In: RAMOS, C.L.N. et al (orgs.). Diálogos sobre direito civil: construindo uma racionalidade contemporânea. Rio de Janeiro: Renovar, 2002.

JORGE JÚNIOR, A.G. Cláusulas gerais no novo Código Civil. São Paulo: Saraiva, 2004.

LUDWIG, M.C. Direito público e direito privado: a superação da dicotomia. In: MARTINS-COSTA, J. (org.). A reconstrução do direito privado. São Paulo: Revista dos Tribunais, 2002.

MARTINS-COSTA, J. A boa-fé no direito privado. São Paulo: Revista dos Tribunais, 2000.

MEIRELLES, J. O ser e o ter na codificação civil brasileira: do sujeito virtual à clausura patrimonial. In: FACHIN, L.E. (org.). Repensando fundamentos do direito civil brasileiro contemporâneo. Rio de Janeiro: Renovar, 2000.

NALIN, P. Do contrato: conceito pós-moderno. Em busca de sua formulação na perspectiva civil-constitucional. Curitiba: Juruá, 2001.

NICOLÒ, R. Le situazioni giuridiche soggetive. [S.I.:s.n.]. p. 129-148.

OPPO, G. Diritto privato e interessi pubblici. In: Rivista di Diritto Civile. Padova: CEDAM, a. 40, n. 1, p. 25-41, 1994.

PERLINGIERI, P. Il Diritto civile nella legalità costituzionale. Napoli, Itália: Edizioni Scientifiche Italiane, 1991.

La personalità umana nell'ordinamento giuridico. Napoli: Jovene, 1972.

REALE, M. Lições preliminares de direito. 27. ed. São Paulo: Saraiva, 2003.

SARLET, I.W. Dignidade da pessoa humana e direitos fundamentais. 2. ed. Porto Alegre: Livraria do Advogado, 2002.

SELEME, S. Contrato e empresa: notas mínimas a partir da obra de Enzo Roppo. In: FACHIN, L.E. (org.). Repensando fundamentos do direito civil brasileiro contemporâneo. Rio de Janeiro: Renovar, 2000.

SZANIAWSKI, E. Direitos de personalidade e sua tutela. 2. ed. São Paulo: Revista dos Tribunais, 2005. 